\title{
Glucosamine synthetase activity of the colonic mucosa in ulcerative colitis and Crohn's disease
}

\author{
M. J. GOODMAN, ${ }^{1}$ P. W. KENT, ${ }^{2}$ AND S. C. TRUELOVE \\ From the Nuffield Department of Clinical Medicine, Radcliffe Infirmary, Oxford
}

SUMMARY Glucosamine synthetase is the first enzyme in glycoprotein biosynthesis, catalysing the formation of glucosamine-6-phosphate, from which $\mathrm{N}$-acetylglucosamine is formed. The levels of this enzyme in normal human colonic mucosa (in colectomy specimens and rectal biopsies) were found to be $13.8 \pm 4.0 \mu \mathrm{mol}$ glucosamine synthesised/h/g wet wt. In the colonic mucosa in ulcerative colitis and Crohn's colitis the enzyme level was diminished when there was loss of epithelial cells in the mucosa, although not when there was just loss of goblet cells. In patients recovering from an acute attack of ulcerative colitis, the enzyme levels rose to a peak above the normal range, an effect which did not occur in patients who did not recover promptly. This recovery peak may be related to the synthesis of gastrointestinal mucus, or immunoglobulin, or the secretory component of $\operatorname{IgA}$, all of which contain large amounts of $\mathrm{N}$-acetylglucosamine.

Glucosamine synthetase (L-glutamine-D-fructose-6phosphate aminotransferase, EC.2.6.1.16) is the cytoplasmic enzyme which catalyses the synthesis of glucosamine-6-phosphate from fructose-6-phosphate and glutamine:

Fructose-6-phosphate Glucosamine-6-phosphate

$$
+\underset{\text { Glutamine }}{\stackrel{\text { Glucosamine }}{\text { synthetase }}}+
$$

It is a rate-limiting step in the biosynthesis of UDP$\mathrm{N}$-acetylglucosamine (Lukie and Forstner, 1972) and also in the biosynthesis of glycoprotein. Duazomycin $A$, an analogue of glutamine, inhibits glucosamine synthetase and inhibits glycoprotein synthesis in rat liver, the latter inhibition being relieved by the addition of exogenous glucosamine (Bates et al., 1966).

The major component of the glycoprotein synthesised by the intestinal mucosa is the secreted mucus (Forstner, 1970; Forstner et al., 1973). However, there are many other glycoproteins in the gastrointestinal tract-in particular, the immunoglobulins (Kent, 1967) and the secretory component

${ }^{1}$ Present address: Department of Medicine, University of Chicago, USA.

${ }^{2}$ Present address: Director, Glycoprotein Research Unit, University of Durham.

Received for publication 14 September 1976
(SC) of secretory IgA (Lamm and Greenberg, 1972).

Glycoproteins consist of a protein backbone on which are assembled complex carbohydrate sidechains. In mucus and in immunoglobulins approximately half of the carbohydrate component is $\mathrm{N}$ acetylglucosamine, $\mathrm{N}$-acetylgalactosamine, or sialic acid (Kent, 1967), and in secretory component the carbohydrate fraction seems also to be mainly $\mathrm{N}$ acetylglucosamine (Lamm and Greenberg, 1972). These particular sugars are supplied to the glycoprotein molecule from UDP-N-acetylglucosamine. There is feedback inhibition of glucosamine synthetase by UDP-N-acetylglucosamine (Kornfeld $e t$ al., 1964).

Glucosamine synthetase has previously been measured in experimental animals, where it has been found principally in liver and also in the stomach and the intestine, but with none detectable in muscle (Kaufman et al., 1971; Kikuchi et al., 1971). There is no published work on its activity in human tissue.

This paper describes the miniaturisation of a method of assay of glucosamine synthetase in order to estimate the levels of the enzyme in rectal biopsies obtained via a sigmoidoscope. It reports the results obtained by measurement of glucosamine synthetase in apparently normal human colonic mucosae and in the mucosa in ulcerative colitis and in Crohn's disease. The study was undertaken in an attempt to identify biochemical differences between ulcerative colitis and Crohn's disease to explain the common 
finding of histological mucus depletion in ulcerative colitis and its rarity in Crohn's disease of the colon (Cook and Dixon, 1973).

\section{Methods}

ASSAY OF GLUCOSAMINE SYNTHETASE The method used was derived from that of Winterburn and Phelps (1971). The assay was miniaturised by adjusting the incubation conditions in order to achieve the maximum yield of glucosamine synthesis. For these miniaturisation studies, the homogenates used were of colonic mucosa obtained by dissection from the submucosa in the normal-looking areas of surgical colectomy specimens for carcinoma of the large bowel. Winterburn and Phelps (1971) incubated homogenates of rat liver with $5 \mathrm{mM}$ fructose-6phosphate and $12 \mathrm{mM}$ glutamine in $50 \mathrm{mM}$ tris- $\mathrm{HCl}$ buffer at $\mathrm{pH} 7.5$ for 90 minutes. It was found that the optimum concentrations of the substrates for glucosamine synthesis by human colonic mucosa were $20 \mathrm{mM}$ fructose-6-phosphate and $8 \mathrm{mM}$ glutamine, improving the yield of glucosamine by $30 \%$ compared with the substrate concentrations used by Winterburn and Phelps (Goodman, 1975). Rat liver glucosamine synthetase has an optimum $\mathrm{pH}$ of 7.5 (Winterburn and Phelps, 1971) but the enzyme in human colonic mucosa was found to have an optimum $\mathrm{pH}$ of about 7.0 and the yield of glucosamine was $8 \%$ greater at this $\mathrm{pH}$ than at $\mathrm{pH}$ 7.5. By extending the duration of the incubation to three hours, a further $70 \%$ increase in the yield of glucosamine was obtained, compared with that at 90 minutes. In view of the possibility of bacterial contamination in a three hour incubation (coliform bacteria contain significant amounts of glucosamine synthetase), gentamicin was included in the incubate, at a concentration of $100 \mu \mathrm{g} / \mathrm{ml}$, which did not interfere with the enzyme reaction or with the colorimetric estimation of glucosamine-6-phosphate. Mucosal homogenates had no less glucosamine synthetase activity than did supernatants of centrifuged homogenates, on which all previous published reports of glucosamine synthetase measurements have been made; in view of this, the degree of miniaturisation was further improved by eliminating the wastage of the centrifuged deposit.

As a result of these adjustments and by using volumes of the order of $0 \cdot 1-0.4 \mathrm{ml}$, a method of assay was used which required only $0.2 \mathrm{ml}$ of an homogenate containing $10 \mathrm{mg}$ tissue per $\mathrm{ml}$. For duplicated readings, this meant that the assay could be performed with just over $4 \mathrm{mg}$ tissue. Rectal biopsies weigh between 5 and $20 \mathrm{mg}$, so that on many occasions only half of a rectal biopsy was needed for the estimation.

\section{DETAILS OF METHOD}

The enzyme incubation had to be started within two hours of removal of the tissue from the body, as the enzyme activity decays by $50-70 \%$ after 24 hours' storage even at $-20^{\circ}$. Rectal biopsies were orientated flat on filter paper and cut in half using a scalpel blade. One half was placed in formol saline for histological examination and the other half was placed in a bottle containing ice-cold buffer, $50 \mathrm{mM}$ $\mathrm{Na}_{2} \mathrm{HPO}_{4} / \mathrm{NaH}_{2} \mathrm{PO}_{4}$ at $\mathrm{pH} 7.0$ containing $100 \mathrm{mM}$ $\mathrm{KCl}$ and $1 \mathrm{mM}$ EDTA. Colectomy specimens were obtained fresh from the operating theatre, portions of the mucosa being removed by blunt dissection and placed in the buffer. Pieces of colonic mucosa from rectal biopsies and colectomy specimens were washed in the same buffer, blotted on filter paper, weighed, and homogenised in fresh buffer to make $0.01 \mathrm{ml}$ homogenate per $0.1 \mathrm{mg}$ tissue. Two $0.2 \mathrm{ml}$ volumes of the homogenate were incubated in a water-bath at $37^{\circ}$ with $0.2 \mathrm{ml}$ volumes of a substrate-buffer mixture containing $8 \mu \mathrm{mol}$ fructose-6-phosphate disodium (Boehringer Mannheim $\mathrm{GmbH}$ ), $3.2 \mu \mathrm{mol}$ L-glutamine, and $\mathbf{4 0} \mu \mathrm{g}$ gentamicin (Genticin Pure Powder, Nicholas Laboratories Ltd), so that the final concentrations of the substrates were $20 \mathrm{mM}$ for fructose-6-phosphate and $8 \mathrm{mM}$ for glutamine. After three hours, the reaction was terminated with $0.02 \mathrm{ml}$ concentrated perchloric acid $(71 \%)$. At this stage, the tubes containing the incubates could be stored in a deep-freeze (although the glucosamine during storage appeared to decay at a rate of $0.4 \%$ per day, requiring the use of a correction factor for stored incubates).

The glucosamine-6-phosphate synthesised was estimated by centrifuging the incubates at $2500 \mathrm{rpm}$ for 15 minutes, taking $0.3 \mathrm{ml}$ of the supernatant, and adding to this $0.02 \mathrm{ml} 8 \mathrm{M} \mathrm{KOH}$ and then a further recorded volume of $\mathrm{M} \mathrm{KOH}$ to a pH between 6 and 11, using Merck non-bleeding indicator strips. Potassium perchlorate was precipitated and $0.2 \mathrm{ml}$ of the solution was taken into a heat-resistant screwcap test-tube, to which was added $0.2 \mathrm{ml}$ of a borate buffer $(1.12 \mathrm{~mol}$ boric acid and $0.56 \mathrm{~mol} \mathrm{KOH}$ per litre, $\mathrm{pH} \mathrm{9.2)} \mathrm{and} \mathrm{then} 0.05 \mathrm{ml}$ acetic anhydride $1.5 \% \mathrm{w} / \mathrm{v}$ in acetone. The screw-cap tubes were placed in a boiling water-bath for three minutes and then in an ice water-bath for a further five minutes. To each tube was then added $1.6 \mathrm{ml}$ dimethylaminobenzaldehyde (DAB), $0.5 \mathrm{~g}$ dissolved in $100 \mathrm{ml}$ glacial acetic acid containing $1 \cdot 25 \mathrm{ml}$ concentrated hydrochloric acid, the tubes being placed immediately in a $37^{\circ}$ water-bath for 20 minutes. The intensity of the colour formed in this, the Morgan-Elson reaction (Morgan and Elson, 1934), was read in a spectrophotometer at $545 \mathrm{~nm}$.

Standard solutions were of glucosamine hydro- 
chloride, $0 \cdot 05,0 \cdot 10,0 \cdot 20$, and $0.30 \mathrm{mM}$, which were treated with similar volumes of perchloric acid and $\mathrm{KOH}$ as the test solutions. A standard curve was constructed for these and a water-blank, plotting the optical density of the colour against glucosamine concentration corrected for the volumes of $\mathrm{KOH}$ and perchloric acid used. The chromogenic capacity of DAB solutions was found to decay by $5-10 \%$ per hour at room temperature and the colour formed in the Morgan-Elson reaction decayed in ice by $2-4 \%$ per hour (Goodman, 1975). No more than 19 test solutions were read with a single batch of standards. The DAB 'solution was added to three tubes every two minutes, the optical density being read as soon as the colour incubation was completed. The duplicated incubates in the enzyme reaction from each homogenate were read with different batches of DAB solution and standards.

With mucosa from colectomy specimens, $0.5 \mathrm{ml}$ volumes of homogenate were used (instead of $0.2 \mathrm{ml}$ volumes) and all other volumes in the method were larger by a factor of $2 \cdot 5$.

Tissue hexosamine levels were too low to be detected by this assay and it proved to be unnecessary to perform control estimations on unincubated homogenates.

Glucosamine-6-phosphate gives only about $80 \%$

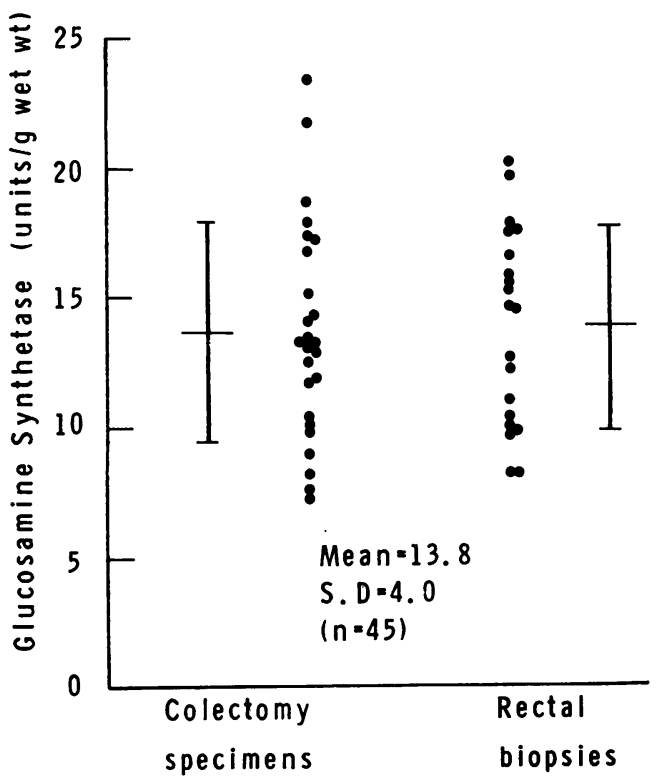

Fig. 1 Glucosamine synthetase levels (in $\mu \mathrm{mol}$ glucosamine synthesised $/ \mathrm{h} / \mathrm{g}$ wet $\mathrm{wt}$ ) in normal colonic mucosa, obtained from the normal cut ends of 25 colectomy specimens (22 removed for carcinoma of the colon and three for localised diverticulitis), and from the rectal biopsies of 20 patients with the irritable colon syndrome. of the colour of glucosamine (Kaufman et al., 1971) but this was ignored and the glucosamine-6phosphate synthesised was expressed as if it were glucosamine in the Morgan-Elson reaction. The units of enzyme activity were $\mu \mathrm{mol}$ glucosamine synthesised/h/g wet wt of tissue. The protein concentration in the homogenate was measured in 76 samples of colonic mucosa (32 samples of normal mucosa, 28 of ulcerative colitis, and 16 of Crohn's colitis) according to the method of Lowry et al. (1951). This enabled the glucosamine synthetase activity per $\mathrm{g}$ tissue protein to be plotted against the activity per $g$ wet weight. There was a close correlation $(r=$ 0.90 ) and it was felt justifiable to express the enzyme activity in biopsies in units per $\mathbf{g}$ wet weight so that tissue did not need to be used for the protein estimation (Goodman, 1975).

NORMAL COLONIC MUCOSA

A normal range for glucosamine synthetase levels in the colonic mucosa was obtained by measuring the enzyme in the histologically normal cut ends of colectomy specimens from 22 patients with carcinoma of the colon and three patients with localised diverticulitis and in the rectal biopsies, taken $10 \mathrm{~cm}$ from the anal margin, of 20 patients with the irritable colon syndrome.

ULCERATIVE COLITIS AND CROHN'S DISEASECOLECTOMY SPECIMENS

Glucosamine synthetase levels were measured in three samples of mucosa from each of 10 panproctocolectomy specimens for ulcerative colitis and two panproctocolectomy specimens for Crohn's disease of the colon. From each specimen, one sample was taken at $10 \mathrm{~cm}$ from the anal margin, one from the area which was most inflamed macroscopically, and one from the least inflamed area. Histological sections of each sample of mucosa were prepared and were examined and the epithelial cell pattern was graded according to the following scheme:

Grade $\boldsymbol{H}$-Hypertrophied crypts present.

Grade 0-Normal crypts.

Grade 1-Distorted crypts.

Grade 2-Epithelium and crypts damaged by the inflammatory process, but without gross diminution in the density of the epithelial cells.

Grade 3-Epithelial cell density clearly diminished.

Grade 4-Epithelial cells very scanty or absent.

ULCERATIVE COLITIS AND CROHN'S DISEASERECTAL BIOPSIES

Glucosamine synthetase levels were measured in rectal biopsies, taken $10 \mathrm{~cm}$ from the anal margin, of 
71 patients with ulcerative colitis, nine patients with Crohn's disease involving the rectum, and 13 patients with Crohn's disease which had never involved the rectum. The epithelial cell pattern was graded as for the colectomy specimens.

Twenty of the patients with ulcerative colitis were suffering from an acute attack of the disease which was treated with the five-day intensive intravenous regimen of Truelove and Jewell (1974), using 40-60 mg prednisolone-21-phosphate daily. In these 20 patients, glucosamine synthetase levels were measured in serial rectal biopsies. The aim was to take biopsies at the time the attack was diagnosed and after five days, 10 days, six weeks, and three months.

\section{Results}

NORMAL COLONIC MUCOSA

The glucosamine synthetase levels in the normal cut ends of the 25 colectomy specimens ( 22 of them for carcinoma) were similar to those in the 20 rectal biopsies from patients with the irritable colon syndrome (Fig. 1). For the combined series of 45 samples of mucosa, the mean glucosamine synthetase activity was 13.77 units ( $\mu \mathrm{mol}$ glucosamine synthesised/h/g wet wt) with a standard deviation of 3.97 units. There were no differences with regard to age or sex and in the colectomy specimens the enzyme activity was similar in all parts of the large intestine from the caecum to the rectum (Goodman, 1975).

The glucosamine synthetase activity in the submucosa was less than 1.0 unit.

In the five patients with the irritable colon syndrome who complained of excessive mucus in their stools, the glucosamine synthetase levels were similar (mean, 14.18 units) to the 15 patients with the irritable colon syndrome who did not have excessive mucus (mean, 13.82 units).

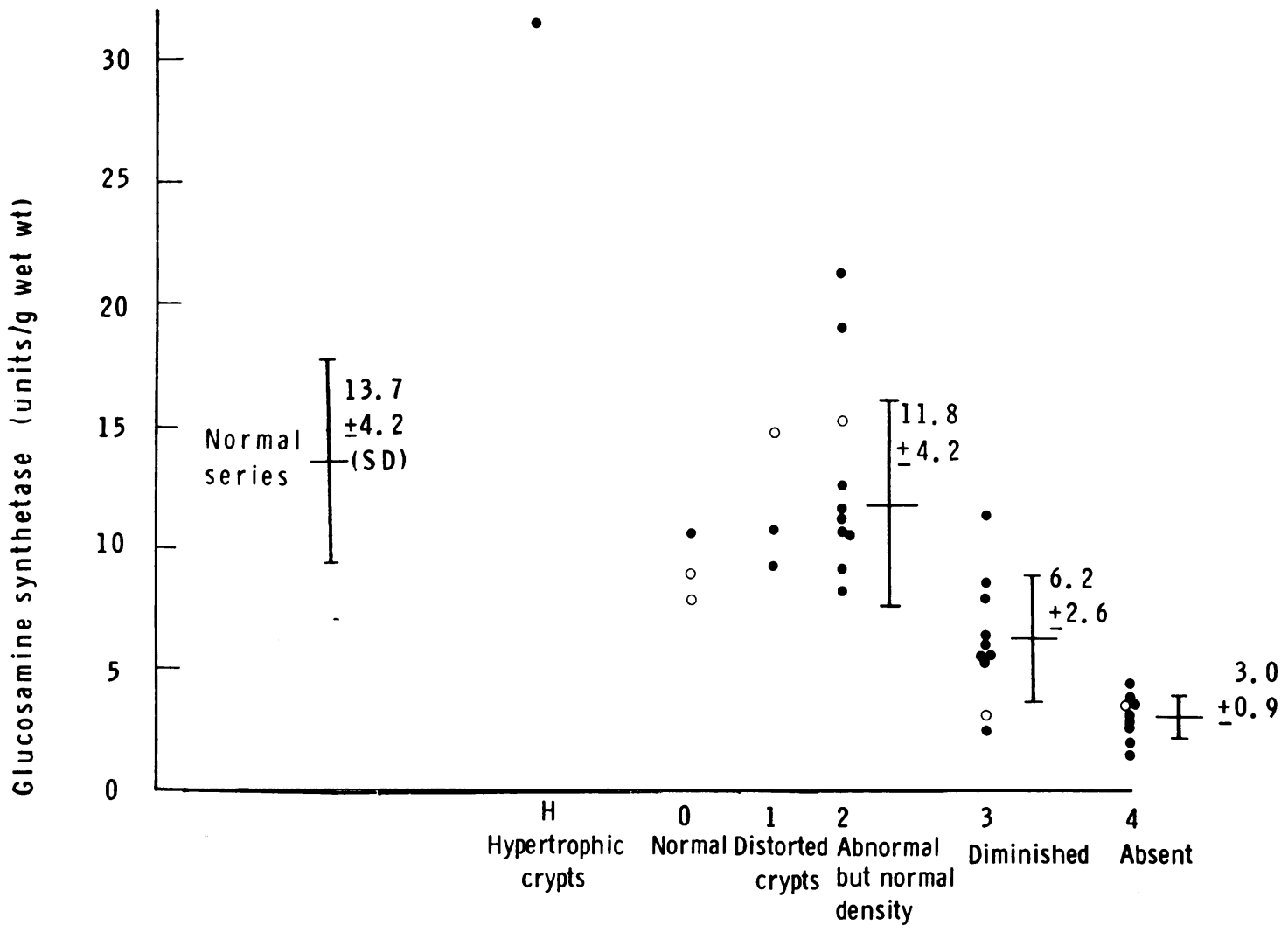

GRADE OFEPITHELIAL CELL DENSITY

Fig. 2 Glucosamine synthetase activity in 36 samples of colonic mucosa taken from 12 panproctocolectomy specimens (10 for ulcerative colitis, two for Crohn's disease) in relation to the graded epithelial cell density. ๑; ulcerative colitis. O; Crohn's colitis. (Mean and SD for grades 0-2 are taken together). 
ULCERATIVE COLITIS AND CROHN'S DISEASECOLECTOMY SPECIMENS

There was a lower mean of glucosamine synthetase levels in the colectomy specimens from patients with ulcerative colitis and Crohn's colitis than in the normal series, but there was a good deal of overlap (Fig. 2). There were no differences between the levels in the 10 patients with ulcerative colitis and those in the two patients with Crohn's disease (nor between these and six other patients with ulcerative colitis and two others with Crohn's colitis whose panproctocolectomy specimens were studied in preliminary work).

However, when the glucosamine synthetase levels were correlated with the epithelial cell density, it it was observed that, whatever the degree of inflammation, the enzyme levels remained normal if the overall epithelial cell density was not grossly diminished (Fig. 2). When there was diminution in the epithelial cell density the glucosamine synthetase levels were lower, although in the samples of mucosa in which the epithelial cells were absent the glucosamine synthetase levels were $3.0 \pm 0.9$ units. The single sample with hypertrophied crypts had a very high glucosamine synthetase level of 31.6 units.

ULCERATIVE COLITIS-RECTAL BIOPSIES

The glucosamine synthetase levels in the rectal biopsies of the 71 patients with ulcerative colitis showed a similar correlation with the overall epithelial cell density, although this was not as marked as with the colectomy specimens (Fig. 3). Patients taking steroids (orally or by enema) had similar enzyme levels to those who were not taking steroids (Fig. 3).

\section{ULCERATIVE COLITIS-GOBLET CELL \\ DEPLETION}

Twelve rectal biopsies from the series with ulcerative colitis in which the goblet cell density was grossly diminished but in which the overall epithelial cell density was normal were selected without reference

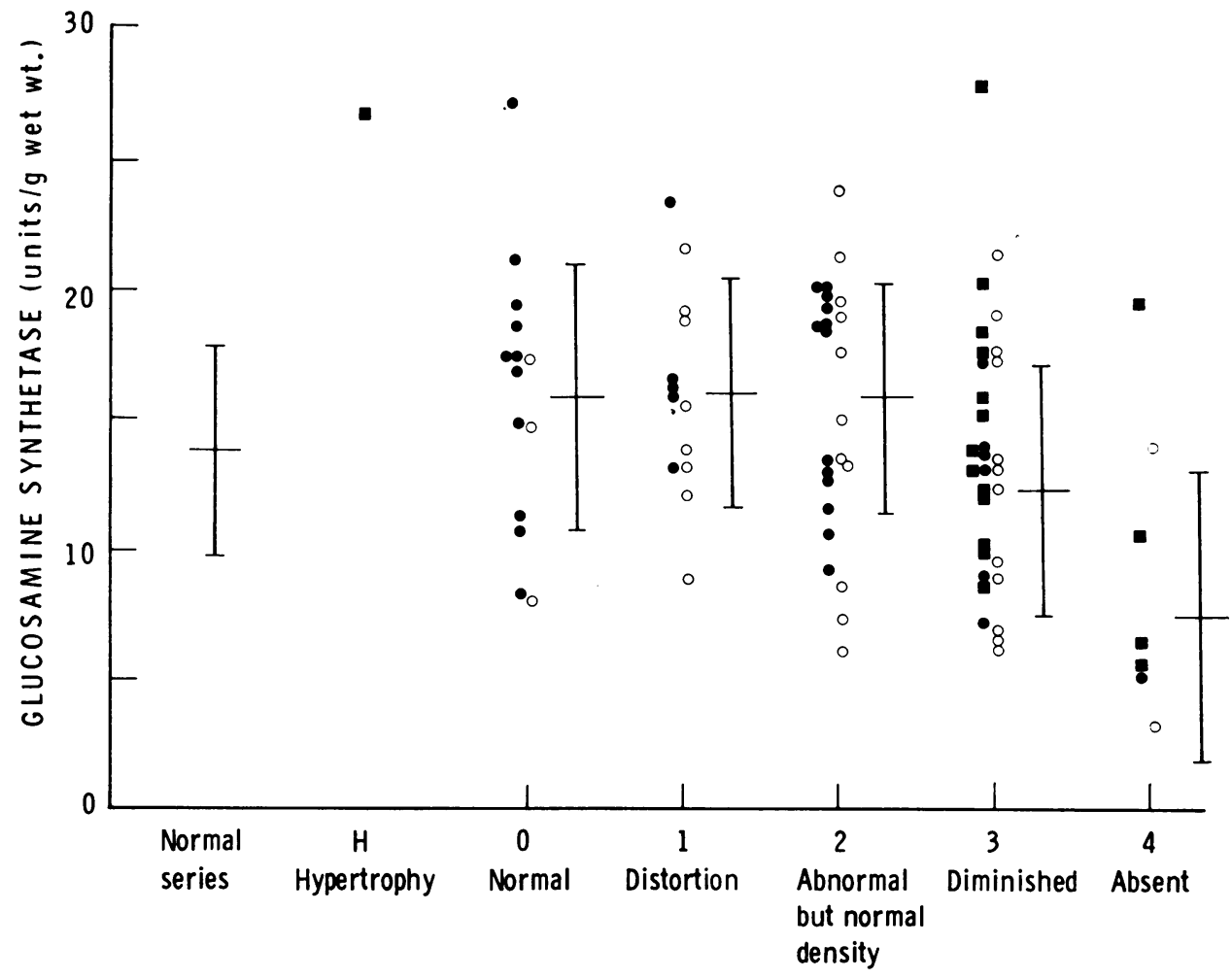

Fig. 3 Glucosamine synthetase in the rectal biopsies of 71 patients with ulcerative colitis according to the grading of the epithelial cell density. Also shown are 20 follow-up biopsies from 13 of these patients, being those biopsies in which the epithelial cell density was graded $\mathrm{H}, 3$ and 4. : initial biopsies, patients taking systemic steroids or steroid enemas. $\square$ : follow-up biopsies, patients on steroids. $\bigcirc$ : initial biopsies, patients not on steroids. Bars show mean and $S D$ for each grade, initial biopsies only. 
to their glucosamine synthetase levels and it was found that the enzyme levels in these biopsies were normal (Fig. 4).

SERIAL RECTAL BIOPSIES IN ATTACK OF ULCERATIVE COLITIS

Fifteen of the 20 patients studied in an acute attack of ulcerative colitis made a prompt recovery within two weeks, as defined by a return of the appearances on sigmoidoscopy to normal or only mild inflammation. All 15 patients showed a similar pattern in their serial glucosamine synthetase levels, with a rise in the enzyme levels to a peak above the normal range followed by a fall to within the normal range (Fig. 5, patient D.M.). Sometimes the enzyme level was already at the peak at the time of the first reading (Fig. 5, patient E.Mo.). In all 15 patients the peak was 19.0 units or more, the mean peak level being 23.94 units, occurring at a mean of 16 days after the first biopsy (which was at the time at which the attack was diagnosed) (Fig. 6). This peak was not simply a steroid effect, because four of the patients (including the patient E.Mo. in Fig. 5) were at their peak or within 1.0 unit of the peak at the first biopsy before any steroids had been given. Also, when $40 \mathrm{mg}$ prednisolone were given daily for one week to four other patients with ulcerative colitis who were in remission there was no change in their glucosamine synthetase levels.

Figure 7 shows the glucosamine synthetase levels in the serial rectal biopsies of the five patients who did not show sigmoidoscopic evidence of recovery

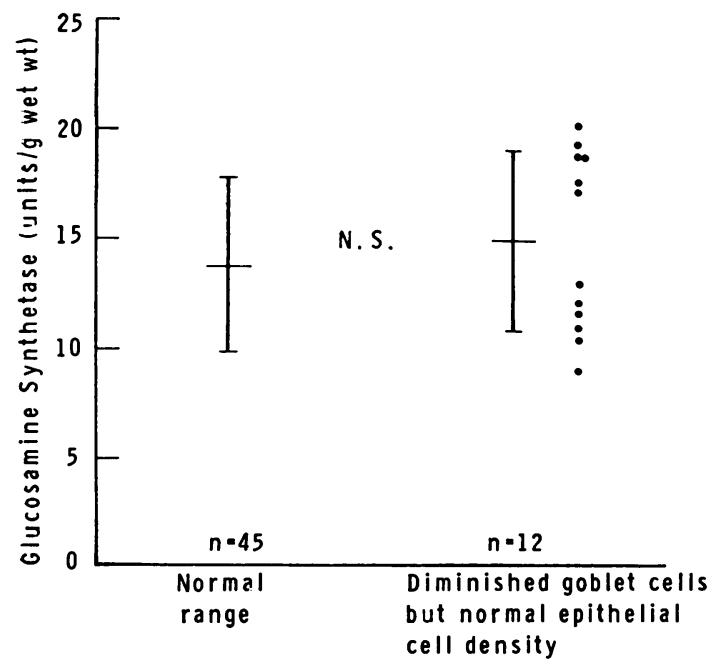

Fig. 4 Glucosamine synthetase levels in 12 rectal biopsies from patients with ulcerative colitis in which there was a normal overall epithelial cell density but in which the goblet cell density was much diminished. from their acute attack of ulcerative colitis. The patient M.Car. was an old lady of 83 years who improved clinically sufficiently to leave hospital on the 15th day but sigmoidoscopically the inflammation remained moderate until the 67th day, when it became mild and the enzyme levels rose to 16.7 units. The two patients H.C. and N.H. had severe attacks of ulcerative colitis, requiring emergency panproctocolectomy on the ninth and 15th day respectively. $\mathrm{P}$.Wh. was a resilient young man who seemed to make a good recovery but his mucosa remained moderately inflamed on sigmoidoscopy and panproctocolectomy was subsequently performed; this showed severe and extensive ulcerative colitis. The patient N.McE. showed some initial improvement but he failed to recover from the attack of colitis and he was treated by panproctocolectomy five weeks after admission. In these patients, the results of the glucosamine synthetase estimations were not available at the time of the decision to operate.

CROHN'S DISEASE-RECTAL BIOPSIES

The glucosamine synthetase levels in the nine biopsies from patients with Crohn's disease involving the rectum had a mean of 14.03 units, similar to that of the normal series, although the standard deviation was greater (Fig. 8). The levels were no different from those in rectal biopsies from patients with ulcerative colitis (Fig. 3).

The glucosamine synthetase levels in the 13 biopsies from patients with Crohn's disease sparing the rectum had a mean of 20.55 units (Fig. 8), considerably higher than that of the normal series $(P<0.001)$ and rather similar to the peak levels in the patients recovering from an attack of ulcerative colitis. Eight of these patients (with a mean of 20.76 units) had never had clinically apparent Crohn's disease distal to the caecum (Goodman et al., 1976).

\section{Discussion}

Glucosamine synthetase has been measured in the normal human colonic mucosa and appreciable levels of the enzyme have been found. There was more glucosamine synthetase in the colonic mucosa than in several samples of human liver tissue that were assayed by the same method $(9-20 \mu \mathrm{mol}$ glucosamine synthesised $/ \mathrm{h} / \mathrm{g}$ wet wt compared with 4-10 units in liver tissue). This contrasts with previously reported animal experiments in which the levels of glucosamine synthetase in the intestine were lower than those in the liver (Kaufman et al., 1971; Kikuchi et al., 1971) but those measurements were apparently made on full thickness intestine including the muscle layers. 


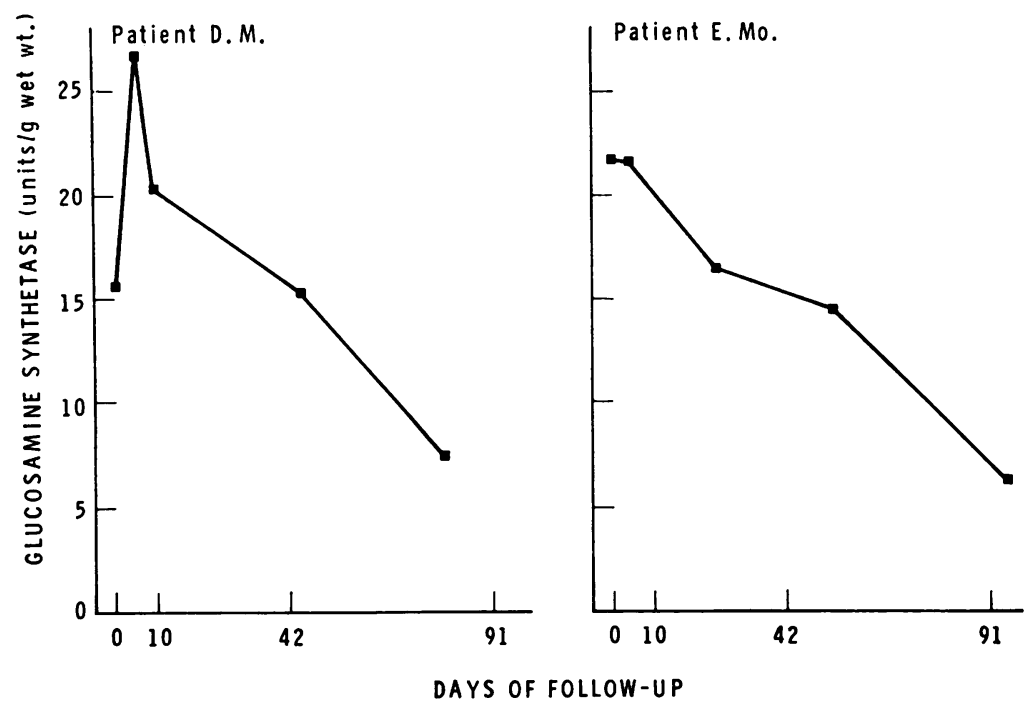

Fig. 5 Glucosamine synthetase levels in serial rectal biopsies of two patients in an acute attack of ulcerative colitis followed by recovery from the attack.

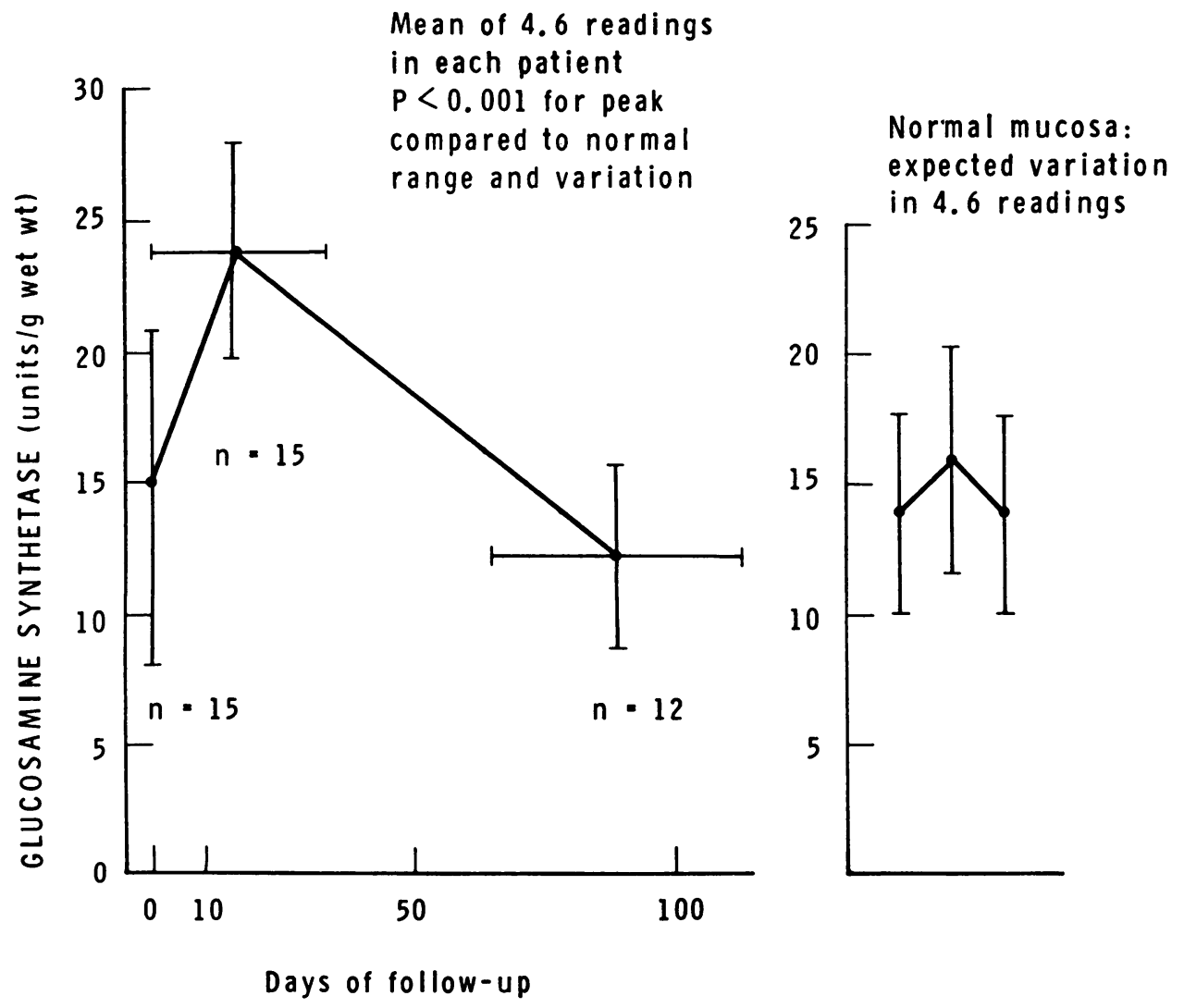

Fig. 6 Glucosamine synthetase levels in serial rectal biopsies of 15 patients in an acute attack of ulcerative colitis treated by the five-day intensive steroid regime who recovered from the attack. (Bars show mean $\pm S D$ ). 

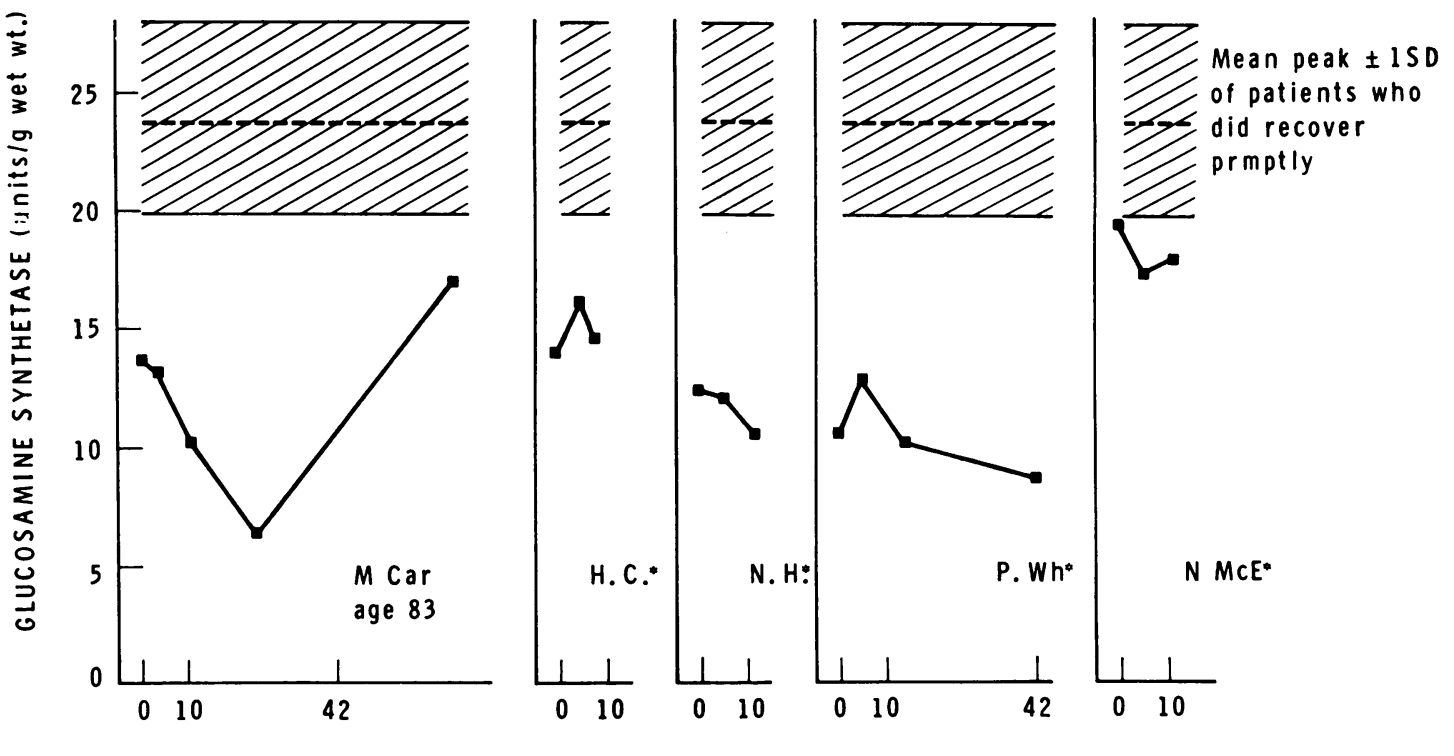

DAYS TO FOLLOW-UP

Fig. 7 Glucosamine synthetase levels in serial rectal biopsies of five patients in an acute attack of ulcerative colitis who did not show sigmoidoscopic evidence of recovery from their attack. *: Panproctocolectomy.

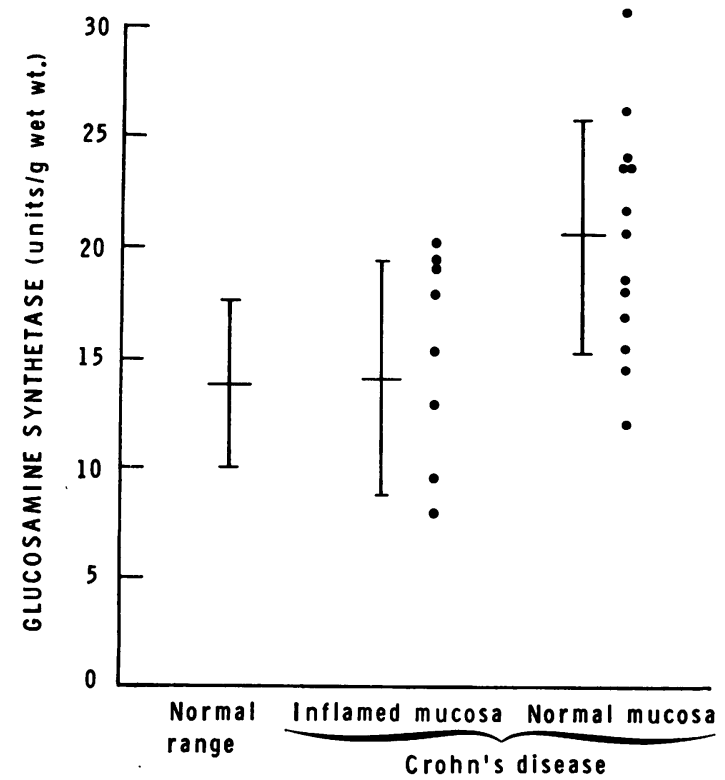

Fig. 8 Glucosamine synthetase levels in recta biopsies in Crohn's disease according to rectal involvement. Bars show mean $\pm S D$.
Glucosamine synthetase is the first enzyme in glycoprotein biosynthesis and it is probably a ratelimiting step. Its activity in the colonic mucosa appears to correlate with the epithelial cell density, although not with the goblet cell density. When the goblet cells are depleted in ulcerative colitis, the glucosamine synthetase levels are normal provided that the epithelial cell density is normal, and the estimation of glucosamine synthetase activity in rectal biopsies does not seem to be helpful in the differentiation of ulcerative colitis and Crohn's disease.

The principal glycoprotein synthesised by the intestinal epithelium is the mucus, which is seen in histological sections in the goblet cells. The fact that mucosae in which the goblet cells are replaced by columnar cells have normal glucosamine synthetase levels need not mean that these mucosae are not synthesising glucosamine-6-phosphate for mucus synthesis. Merzel and Leblond (1969), in studies on the mouse small intestine, showed that the precursors of goblet cells appear to be columnar cells.

The two samples of mucosa with hypertrophied crypts (grade $\mathbf{H}$ ) had particularly high glucosamine synthetase levels, 31.6 units in the colectomy 
sample (Fig. 2) and 26.8 units in the one biopsy with hypertrophied crypts (Fig. 3).

On the other hand, the immunoglobulins are glycoproteins and inflammatory cells contain significant amounts of glucosamine synthetase. Schönhöfer and Anspach (1967) found raised levels of glucosamine synthetase in the inflammatory tissue of the walls of granulomata induced in rats by carrageenin. The samples of mucosa from the panproctocolectomy specimens with severe colitis and absent epithelial cells had glucosamine synthetase levels of $3.0 \pm 0.9$ units, and one sample of severely inflamed submucosa from a colectomy specimen for ulcerative colitis had a level of 1.6 units. However, the immunoglobulins are not synthesised by the epithelial cells and the correlation of the enzyme levels with the epithelial cell density would make it unlikely that the major part of the glucosamine synthetase in the mucosal specimens is derived from the immunocytes.

The secretory component (SC) of IgA is a glycoprotein which is found in the non-mucous columnar cells of the colon but not in the goblet cells (Poger and Lamm, 1974). Its absence from the goblet cells is not in favour of its production being related to mucosal glucosamine synthetase levels.

The rise to a peak of the glucosamine synthetase activity in the rectal mucosa during recovery from an acute attack of ulcerative colitis, a peak which is well above the normal range and is therefore not simply a reflection of a return to normal of depleted epithelial cells, corresponds to the rise in glucosamine synthetase levels in neonatal rat liver after partial hepatectomy that was shown by Akamatsu and Maeda (1971) and by Bley et al. (1973). This favours the peak being a function of epithelial cell glycoprotein synthesis, probably mucus synthesis, rather than the alternative possibility of an increase in immunoglobulin synthesis in the lamina propria (Skinner, 1975). An increase in the synthesis of another cellular glycoprotein, such as secretory component (SC), cannot be excluded: studies of SC in the goblet cells in the recovery phase of ulcerative colitis have not been reported.

The peak effect in ulcerative colitis appears to be a manifestation of recovery and the absence of such a peak in serial measurements of the glucosamine synthetase activity of rectal biopsies seems to have a predictive value with regard to eventual recovery from the attack (Figs. 6 and 7). As discussed above, the peak effect does not appear to be an effect of steroids, although a peak can be expected to occur if the mucosa recovers as a result of steroid therapy.

The 10 patients with ulcerative colitis and the two patients with Crohn's colitis from whose colectomy specimens the 36 samples of mucosa in Fig. 2 were taken had all failed to respond to medical treatment.
On the other hand, the 71 patients with ulcerative colitis whose biopsy glucosamine synthetase levels are shown in Fig. 3 were patients who were considered to have the possibility of recovery from their attack and many of them were not in an acute attack. Hence, the higher range of glucosamine synthetase levels in the biopsies with epithelial grades 3 and 4 (diminished and absent epithelial cells, respectively) can be accounted for by there being a degree of recovery in these patients that was not the case with the colectomy samples in grades 3 and 4. The glucosamine synthetase level in the colonic mucosa in ulcerative colitis thus appears to be the outcome of two factors, the epithelial cell density and the existence of a recovery phase after an attack.

The high levels of glucosamine synthetase in the morphologically normal rectal mucosa of patients with Crohn's disease elsewhere in the bowel, including patients who had had segments of Crohn's disease resected several years previously without any clinical evidence of further disease, suggest that Crohn's disease is really a diffuse disease even though its overt manifestations are patchy and focal (Goodman et al., 1976). While the estimation of the glucosamine synthetase activity of the rectal biopsy may be of no value in the differential diagnosis of ulcerative colitis and Crohn's disease, it may prove useful in the identification of patients with Crohn's disease when the sigmoidoscopic appearances are normal. A level of more than $\mathbf{2 0 . 0}$ units is suggestive of there being Crohn's disease somewhere in the bowel.

It might be of interest to compare these results for glucosamine synthetase in the healing mucosa in ulcerative colitis with variations in the levels of other enzymes. One difficulty in using homogenates of mucosal biopsies to study enzyme levels is the inclusion in the biopsy of muscularis mucosae, which may be a greater source of enzymes (such as hexokinase and lactic dehydrogenase) than the epithelium itself (Evans and Burdett, 1973). Glucosamine synthetase has the advantage of being rather specific for the epithelial cells, at least in the gut. However, there must be other enzymes specific for epithelial cells, for instance other enzymes of glycoprotein synthesis such as glucosamine-6-phosphate $\mathrm{N}$ acetylase, which could be miniaturised for use with rectal biopsies.

M.J.G. acknowledges the generous support of the Wellcome Trust and P.W.K. that of the Cystic Fibrosis Research Foundation.

\section{References}

Akamatsu, N., and Maeda, H. R. (1971). Formation of 
glucosamine-6-phosphate in regenerating rat liver. Biochimica et Biophysica Acta, 244, 311-317.

Bates, C. J., Adams, W. R., and Handschumacher, R. E. (1966). Control of the formation of uridine diphospho-Nacetylhexosamine and glycoprotein synthesis in rat liver. Journal of Biological Chemistry, 241, 1705-1712.

Bley, R. L., Okubo, H., and Chandler, A. M. (1973). Regulation of glucosamine synthesis in injury and partial hepatectomy. Proceedings of the Society of Experimental Biology and Medicine, 144, 134-140.

Cook, M. G., and Dixon, M. F. (1973). An analysis of the reliability of detection and diagnostic value of various pathological features in Crohn's disease and ulcerative colitis. Gut, 14, 255-262.

Evans, E. M., and Burdett, K. (1973). The use of isolated cells to assess the contribution of the mucosal epithelium to the metabolism of the intestinal wall. Gut, 14, 98-103.

Forstner, G. (1970). [1-14 C] Glucosamine incorporation by subcellular fractions of small intestinal mucosa. Journal of Biological Chemistry, 245, 3584-3592.

Forstner, J., Taichman, N., Kalnins, V., and Forstner, G. (1973). Intestinal goblet cell mucus: isolation and identification by immunofluorescence of a goblet cell glycoprotein. Journal of Cell Science, 12, 585-602.

Goodman, M. J. (1975). Glucosamine Synthetase in the Human Gastrointestinal Mucosa in Health and Disease. D.Phil. Thesis: University of Oxford.

Goodman, M. J., Skinner, J. M., and Truelove, S. C. (1976). Abnormalities in the apparently normal bowel mucosa in Crohn's disease. Lancet, 1, 275-278.

Kaufman, M., Yip, M. C. M., and Knox, W. E. (1971). Glucosamine 6-phosphate synthesis in normal and neoplastic rat tissues. Enzyme, 12, 537-544.

Kent, P. W. (1967). Structure and function of glycoproteins. Essays in Biochemistry, 3, 105-151.

Kikuchi, H., Kobayashi, Y., and Tsuiki, S. (1971). L:Glutamine:D-fructose 6-phosphate amidotransferase in tumors and the liver of tumor-bearing animals. Biochimica et Biophysica Acta, 237, 412-421.
Kornfeld, S., Kornfeld, R., Neufeld, E. F., and O'Brien, P. J. (1964). The feedback control of sugar nucleotide biosynthesis in liver. Proceedings of the National Academy of Sciences, Washington, 52, 371-379.

Lamm, M. E., and Greenberg, J. (1972). Human secretory component. Comparison of the form occurring in exocrine immunoglobulin A to the free form. Biochemistry, 11, 2744-2750.

Lowry, O. H., Rosebrough, N. J., Farr, A. L., and Randall, R. J. (1951). Protein measurement with the Folin phenol reagent. Journal of Biological Chemistry, 193, 265-275.

Lukie, B. E., and Forstner, G. G. (1972). Synthesis of intestinal glycoprotein. Incorporation of $\left[1-{ }^{14} \mathrm{C}\right]$-glucosamine in vitro. Biochimica et Biophysica Acta, 261, 353-364.

Merzel, J., and Leblond, C. P. (1969). Origin and renewal of goblet cells in the epithelium of the mouse small intestine. American Journal of Anatomy, 124, 281-306.

Morgan, W. T. J., and Elson, L. A. (1934). A colorimetric method for the determination of $\mathrm{N}$-acetylglucosamine and $\mathrm{N}$-acetylchondrosamine. Biochemical Journal, 28, 988-995.

Poger, M. E., and Lamm, M. E. (1974). Localisation of free and bound secretory component in human intestinal epithelial cells. A model for the assembly of secretory IgA. Journal of Experimental Medicine, 139, 629-642.

Schonhofer, P., and Anspach, K. F. (1967). Die Aktivităt der L-Glutamin-D-Fructose-6-phosphat-Aminotransferase im Verlauf einer durch Carrageenin induzierten Entzündung und ihre Hemmbarkeit durch Phenylbutazon. Archives Internationales de Pharmacodynamie et de Therapie, 166, 382-389.

Skinner, J. M. (1975). The immunocytes of the gastrointestinal tract. In Topics in Gc stroenterology 3, pp. 227-243. Edited by S. C. Truelove and M. J. Goodman. Blackwell: Oxford.

Truelove, S. C., and Jewell, D. P. (1974). Intensive intravenous regimen for severe attacks of ulcerative colitis. Lancet, 1, 1067-1070.

Winterburn, P. J., and Phelps, C. F. (1971). Purification and some kinetic properties of rat liver glucosamine synthetase. Biochemical Journal, 121, 701-709. 